Brit. J. Ophthal. (1959) 43, 128.

\title{
OBITUARY
}

ANDRÉ MAGITOT

$1877-1958$

The death of Magitot is a loss which will be felt far beyond the boundaries of French ophthalmology, for he had attained the position of a world figure of repute, particularly in ophthalmic physiology and its application to disease.

Magitot became an interne des hopitaux in Paris in 1903 and in 1907 served in the clinic of Victor Morax; in 1935 he succeeded Poulard at the Lariboisière where, apart from his necessary flight during the German occupation of Paris because of his Jewish origin, he remained as senior surgeon until he was succeeded by Edouard Hartmann in 1946. Thereafter his interest in ophthalmology continued unabated, and he retained his active editorship of the Annales d'Oculistique until his sudden death at the age of 82, on September 6, 1958, just as he was preparing to come to the International Congress in Brussels.

There is no doubt that Magitot was one of the most able and original of the ophthalmologists of a previous generation. His initial researches concerned the development of the eye, based on his personal collection of seventy human embryonic and foetal eyes of all ages, as well as the circulation in the optic nerve and chiasma. There followed his classical researches on the nature of the aqueous humour, the ocular circulation, and the control of the intra-ocular pressure. He was the first to demonstrate the viability of the cornea after death and was a pioneer in the application of this knowledge to the practice of corneal grafting. But the work for which he will be most remembered is his life-study of the pathogenesis and clinical features of primary glaucoma which he pictured as a medical disease usually of mesencephalic origin; in a long series of papers he insisted that the rise in ocular tension was merely a symptom, the mechanical relief of which by surgery was palliative but not curative. The brilliance of his intellect, the enthusiasm with which he threw himself into his work, and the originality of his views earned him a unique place among the ophthalmologists of France, and the breadth of his culture and the attractiveness of his personality endeared him to many in a much wider circle.

\section{ALEXANDER MELLICK}

Alexander Mellick was a studious and kindly ophthalmologist who died suddenly on October 19, 1958. He qualified at Glasgow in 1926, taking the admirable B.Sc., M.B., Ch.B. course of those days with Commendation. He was an assistant physician to OutPatients at the Glasgow Royal Infirmary for several years and, at the same time, engaged in general practice. It was during this period that he prepared a thesis on Hepatic Efficiency for the degree of M.D. In 1933 he was appointed a clinical assistant to the Glasgow Eye Infirmary; he worked his way through the various staff appointments, served during the war as an ophthalmic specialist with the rank of major, and on his demobilization in 1946, was made a surgeon in charge of beds at the Southern General Hospital. He was also ophthalmic surgeon to the Glasgow Fever Hospitals and Sanatoria. In 1949 he was admitted a Fellow of the Royal Faculty of Physicians and Surgeons and became a Surgeon to the Glasgow Eye Infirmary. He was a member of the Ophthalmological Society of the United Kingdom and of the Oxford Ophthalmological Congress, and contributed several papers to the British Journal of Ophthalmology on aspects of squint. Alexander Mellick was a good amateur pianist with a deep appreciation of music. We have lost a quiet and retiring colleague at the relatively early age of 55 . 